\title{
DETECTION OF ENTEROTOXINS OF AEROMONAS HYDROPHILA BY A SUCKLING-MOUSE TEST
}

\author{
Valerie Burke, Jennifer Robinson, R. J. Berry and M. Gracey \\ Gastroenterological Research Unit, Princess Margaret Children's Medical Research \\ Foundation, Perth, Western Australia
}

Plate XXVIII

\begin{abstract}
Summary. The suckling-mouse assay was reliable for detecting enterotoxigenic strains of Aeromonas hydrophila when standard conditions for growth and toxin testing were used. Enterotoxins were produced by bacteria grown in tryptone soya broth supplemented with yeast extract and aerated by shaking in an environmental incubator or water bath. When culture supernates together with dye were administered intragastrically to mice less than 6 days old, the presence of enterotoxin was assessed on the basis of a scoring system that incorporated the ratio intestinal weight:remaining body weight, and production of diarrhoea. This method should facilitate the detection of enterotoxigenic strains of Aeromonas in epidemiological studies.
\end{abstract}

\section{INTRODUCTION}

Although the infant-mouse assay system (Dean et al., 1972) has become generally accepted for the detection of heat-stable enterotoxin (ST) of Escherichia coli, it has been used less frequently for the study of enterotoxins produced by other organisms. The purposes of the present study were to investigate the cultural conditions required for the production of the enterotoxins by strains of Aeromonas hydrophila and to assess the suitability of the suckling-mouse assay for their detection.

\section{MATERIALS AND METHODS}

Organisms. One hundred and three strains of $A$. hydrophila, identified by the criteria of Schubert (1974), were investigated: 43 were isolated from stool specimens submitted to the microbiology laboratory at Princess Margaret Hospital, Perth, Western Australia; others were obtained from the South Australian Institute of Technology, Adelaide (51 strains); the Christian Medical College, Vellore, India (6); and the International Centre for Diarrhoeal Disease Research, Bangladesh (3). They were stored for up to 6 months in maintenance medium that contained Bacto Peptone (Difco, O118) $2.5 \mathrm{~g}$, Peptone (Oxoid, L34) 2.5 g, NaCl 5 g, Na $\mathrm{HPO}_{4}$ $2.8 \mathrm{~g}, \mathrm{KH}_{2} \mathrm{PO}_{4} 1.3 \mathrm{~g}$ and agar $5 \mathrm{~g} /$ litre of water $(p \mathrm{H} \mathrm{6.7)}$.

Bacterial preparations and cultural conditions. TSB-YE was Tryptone Soya Broth (Oxoid) supplemented with $0.6 \%$ (w/v) Yeast Extract (Oxoid), and BHI was Brain Heart Infusion Broth 
(B.B.L., Cockeysville, Md, USA). Broth was dispensed in 5-ml amounts in 25-ml Erlenmeyer flasks. Strains of Aeromonas were incubated for $24 \mathrm{~h}$ at $37^{\circ} \mathrm{C}$ in static broth, in broth shaken in a water bath at 100 oscillations/min or in broth agitated at 300 or $100 \mathrm{rpm}$ in a gyratory environmental incubator shaker (New Brunswick Scientific, Edison, NJ, USA).

The time course of enterotoxin production was established in experiments in which broths, seeded with $c .5 \times 10^{4}$ bacteria from an 8-h starter culture of an enterotoxigenic strain of $A$. hydrophila, were shaken at 300 or $100 \mathrm{rpm}$. From duplicate flask cultures, removed at 2-h intervals from 0 to $8 \mathrm{~h}$ and at 12 and $24 \mathrm{~h}$, samples were taken for bacterial counts and enterotoxin assay.

The supernates obtained after centrifugation of the broth cultures, at $3000 \mathrm{rpm}$ for $30 \mathrm{~min}$, were filtered (0.45- $\mu \mathrm{m}$ Millipore type-HA filter; Millipore Corp., Bedford, Mass, USA), and the resulting cell-free preparations, kept at $4^{\circ} \mathrm{C}$, were tested within $24 \mathrm{~h}$.

Osmolality of cell-free filtrates of broth cultures was measured with a Halbmikro osmometer (Knauer and Co., West Berlin).

Enterotoxin assay by a suckling-mouse test. Test supernates (100 $\mu \mathrm{l})$ containing c. $0.05 \%$ (w/v) Pontamine Sky Blue (Searle, High Wycombe, Bucks) were given, intragastrically via a fine, polyethylene tube, of external diameter $0.6 \mathrm{~mm}$, connected to a 1-ml syringe, to 2-6-day-old Swiss albino mice; three or more mice were used in each test. In some experiments, designed to determine the influence of the age of the mice on the assay of enterotoxin, we used suckling mice, more than 6 days old, that had an obvious covering of fur. Control enterotoxin-positive and enterotoxin-negative strains were included in each assay.

Mice were placed on a sheet of blotting paper in a partitioned metal tray, with not more than two mice in each compartment $\left(0.035 \mathrm{~m}^{2}\right)$ and incubated for $3 \mathrm{~h}$ at 28 or $22^{\circ} \mathrm{C}$, and a relative humidity of $39 \%$, in a Memmert incubator. The time course of the response of mice to enterotoxin was determined by examination of mice at intervals up to $3 \mathrm{~h}$ after administration of the test broth.

After incubation, mice were killed by cervical dislocation. Gastric distension and the presence of dye in the small intestine were recorded before removal of the entire gut. Intestinal weight (IW) and remaining body weight (BW) were measured for each group; the IW: BW ratio was calculated and scored on an arbitrary scale from 0 to $4+$, as follows: $<0 \cdot 070=0$; $0.070-0.079=1+; 0.080-0.089=2+; 0.090-0.099=3+;>0 \cdot 100=4+. \quad$ In addition, the amount of diarrhoea produced by each group was observed and estimated on a scale from $1+$ to $4+$ by the intensity of blue staining of the blotting paper placed below the compartments occupied by a batch of mice (see fig. 1). Unstained paper or paper that showed regurgitated dye was scored as 0 . The combined (or total) score was the sum of the scores of the IW: BW ratio and of the amount of diarrhoea; and for each group of mice a total score of 2 or more indicated that a strain was enterotoxigenic.

\section{RESULTS}

\section{Validation of the scoring system}

When tested in the suckling-mouse assay system, each of eight replicate samples of a cell-free preparation from an enterotoxigenic strain of $A$. hydrophila gave a total score of at least 2 (mean 3.63, SEM 0.42). When different cell-free preparations from the same enterotoxigenic strain were tested on 18 different days (fig. 2), each test was positive according to the total score index (mean 4.11, SEM 0.52). In, respectively, two and six of these experiments, the use of the IW: BW ratio alone would have suggested that the cell-free supernate was not enterotoxic, i.e., a value $<0.08$. The use of the diarrhoea score as the sole index of enterotoxic activity would have suggested that the preparation was non-enterotoxic in one test. When, however, the 


\section{ENTEROTOXINS OF AEROMONAS HYDROPHILA}
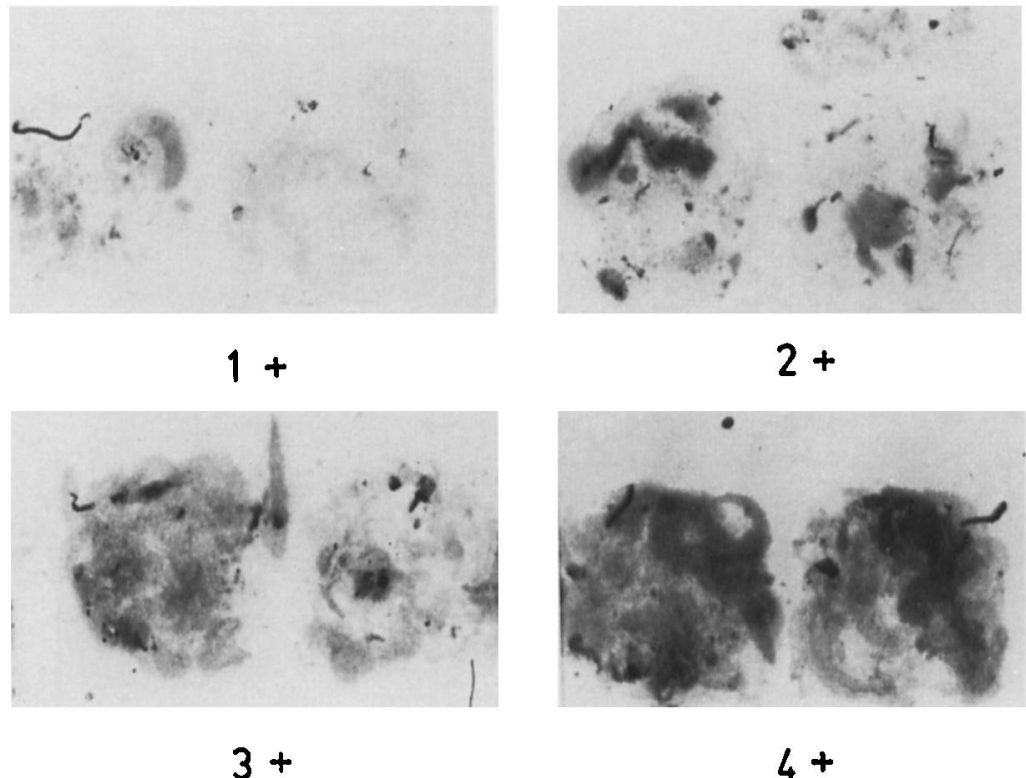

$3+$

$4+$

FIG. 1.-Examples of the degree of staining of blotting paper by different amounts of diarrhoea with indicated scores from $1+$ to $4+$. 


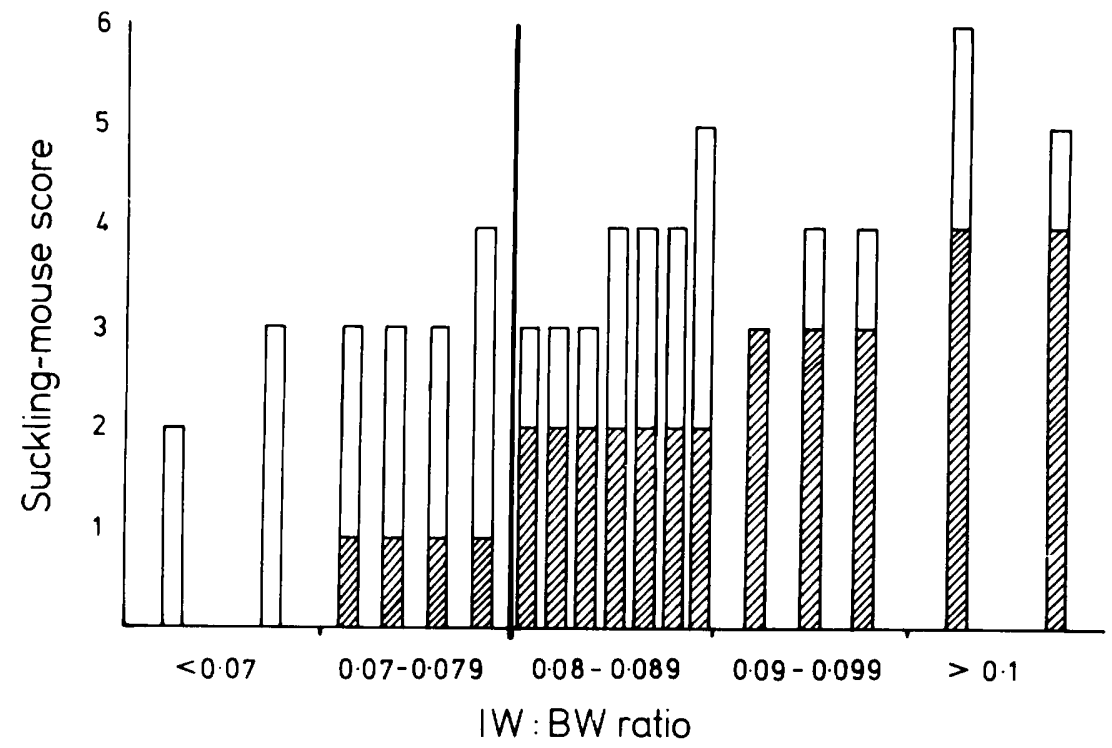

FIG. 2.-Comparison of total scores in the suckling-mouse assay with IW: BW ratios for 18 different preparations from an enterotoxigenic strain of Aeromonas hydrophila. Contributions to the total scores made by scores from IW: BW ratio (hatched) and diarrhoea (unhatched) are indicated.

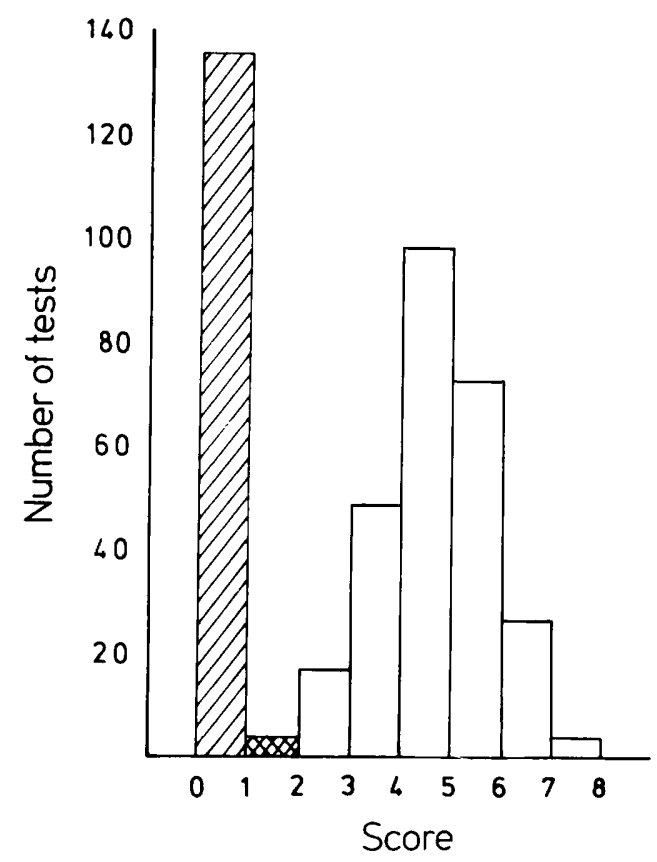

FIG. 3-The distribution of total scores in the suckling-mouse assay with number of tests performed on 103 strains of Aeromonas hydrophilia. $\quad$ = Negative; $8=$ re-test; $\square=$ positive. 
combined scoring system was used, positive results were obtained in all tests.

Preparations that in the suckling-mouse assay gave high IW:BW ratios generally produced little diarrhoea, whereas those that produced profuse diarrhoea usually had low IW:BW ratios. Regression analysis showed that this relationship was statistically significant $(\mathrm{p}<0.05)$.

The distribution of total scores obtained for the 103 strains in 394 individual tests showed that there were two distinct populations of strains (fig. 3 ). There were only four strains, two from each group, that gave scores of 1 and needed further testing for definitive classification.

\section{Enterotoxin production}

In preliminary experiments, 14 strains of $A$. hydrophila were tested for their ability to produce enterotoxin in different cultural conditions. When grown in TSB-YE or BHI at $300 \mathrm{rpm}$, five strains consistently gave total scores of 2 or more in the suckling-mouse assay and a sixth strain, apparently negative in cultures shaken at $300 \mathrm{rpm}$, was positive when grown in TSB-YE or BHI at 100 $\mathrm{rpm}$. The results for the other eight strains were generally negative in the suckling-mouse assay but the results were more consistent when strains were cultured in TSB-YE than in BHI. Thus, the three negative strains that on occasion gave scores of 1 , and, hence, needed retesting, did so more frequently with enterotoxin preparations from cultures grown in BHI than in TSB-YE, and one strain, negative in the suckling-mouse test on 10 occasions, gave a suckling-mouse score of 3 after culture in BHI. Seven of 10 strains, classified as positive after growth in TSB-YE at both speeds, were negative after growth in static TSB-YE.

Of the 103 isolates of $A$. hydrophila, 80 were positive and 23 were negative when tested in the suckling-mouse assay after aeration for $24 \mathrm{~h}$ in TSB-YE. Apart from the above-mentioned strain, positive only in cultures grown at the lower speed, none of the other 102 strains gave discrepant results at the two shaking speeds tested.

In TSB-YE cultures, inoculated with bacteria from an 8-h starter culture of an enterotoxigenic strain, enterotoxins could be demonstrated 2 and $4 \mathrm{~h}$ after inoculation and incubation with aeration at, respectively, 300 and $100 \mathrm{rpm}$ (fig. 4).

The effect of temperature on the activity of cell-free preparations from 32 suckling-mouse-positive strains was tested. After heating at $56^{\circ} \mathrm{C}$ for $10 \mathrm{~min}$, only one preparation retained its enterotoxin activity (score 5); after heating at $100^{\circ} \mathrm{C}$ for $30 \mathrm{~min}$, none was active. All preparations were active after dialysis.

The mean values of the osmolalities of cell-free preparations of $A$. hydrophila from TSB-YE cultures (399.9 mOsm, SEM 6.8) and from BHI cultures $(419.4$ mOsm, SEM, 3.1) were significantly different $(p<0.05)$.

\section{The suckling-mouse assay}

Whereas in tests on eight groups of unfurred mice less than 6 days old of 


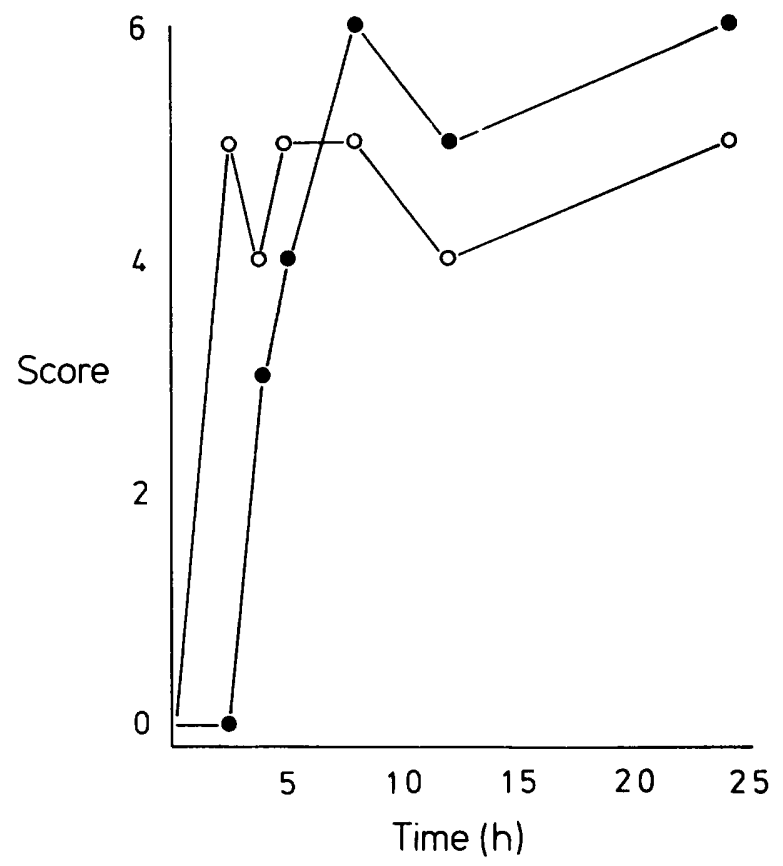

FIG. 4-Time course of enterotoxin production in TSB-YE cultures inoculated from a starter culture of an enterotoxigenic strain of Aeromonas hydrophila, and aerated at $100(\bullet-\bullet)$ and $300(0-0) \mathrm{rpm}$.

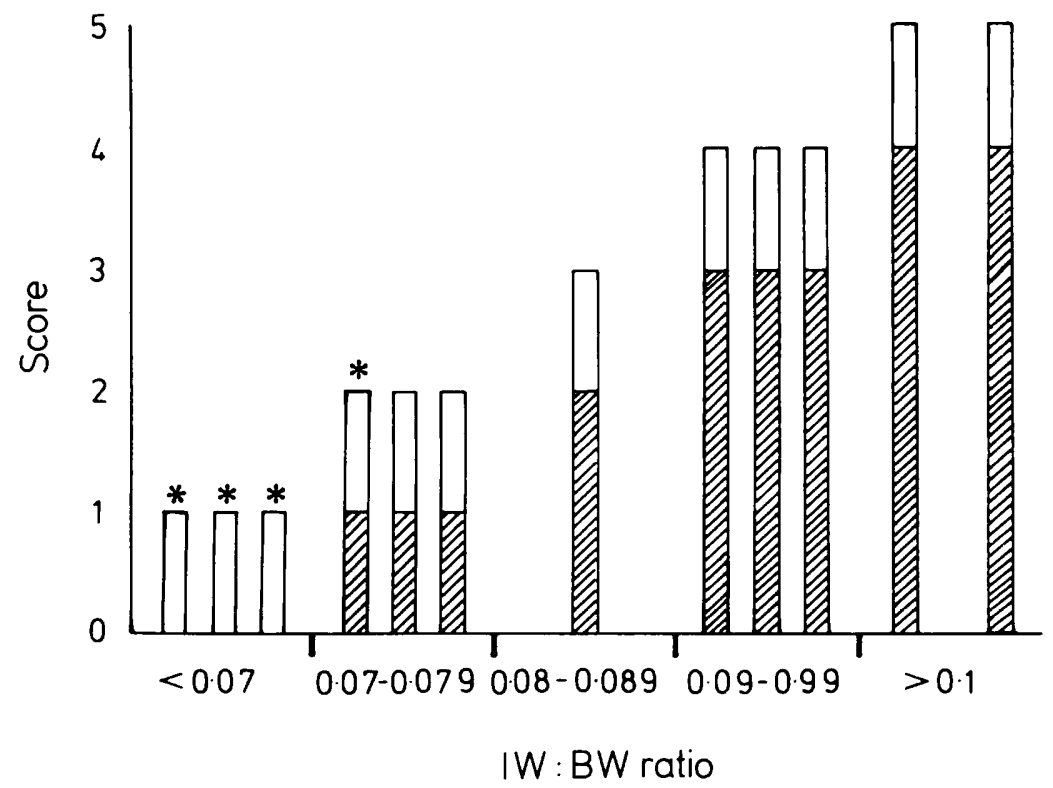

FIG. 5-Comparison of total scores with IW: BW ratios for enterotoxin preparation from an enterotoxigenic strain of Aeromonas hydrophila tested in suckling mice less than, or more than ${ }^{(*)}$, six days old. Total scores, as in fig. 2. 
enterotoxin preparations from a positive strain, a total score of 2 or more was achieved in every experiment, similar tests on four groups of furred mice older than 6 days gave the correct, i.e., positive, result in only one experiment (fig. 5).

Of 14 strains, 13 were correctly classified as either toxigenic or non-toxigenic regardless of whether mice were tested at $22^{\circ} \mathrm{C}$ or $28^{\circ} \mathrm{C}$. The other strain gave the correct, positive, result at $28^{\circ} \mathrm{C}$ but scored zero in tests at $22^{\circ} \mathrm{C}$. The IW : BW ratios were generally lower in animals held at $28^{\circ} \mathrm{C}$ than in those held at $22^{\circ} \mathrm{C}$ whereas diarrhoea was present in greater amounts in animals incubated at the higher temperature. However, the total score was not significantly different at these two temperatures. The results in fig. 6 show that it was possible to identify known positive and negative strains correctly by as early as $2 \mathrm{~h}$ when the suckling mice were kept at $28^{\circ} \mathrm{C}$ but that discrimination was better at $3 \mathrm{~h}$.

After incubation for $3 \mathrm{~h}$ at $28^{\circ} \mathrm{C}, 40$ of $72\left(56^{\circ} \%\right)$ infant mice, inoculated with a cell-free preparation from an enterotoxigenic strain of Aeromonas, and 26 of $51(51 \%)$ mice, inoculated with material from a non-toxigenic strain of Aeromonas, had gastric distension; the proportions were similar in tests at $22^{\circ} \mathrm{C}$ and in those of shorter incubation period.

Blue dye was present in the intestine of all animals regardless of whether they had been tested with broth samples from suckling-mouse-positive or -negative strains. In tests with the former, blue dye extending the whole length of the intestinal tract was seen in 50 of 72 mice $(69 \%)$, whereas in tests with the latter, dye extended as far as the descending colon but was absent from the distal colon in 17 of 21 mice $(81 \%)$.

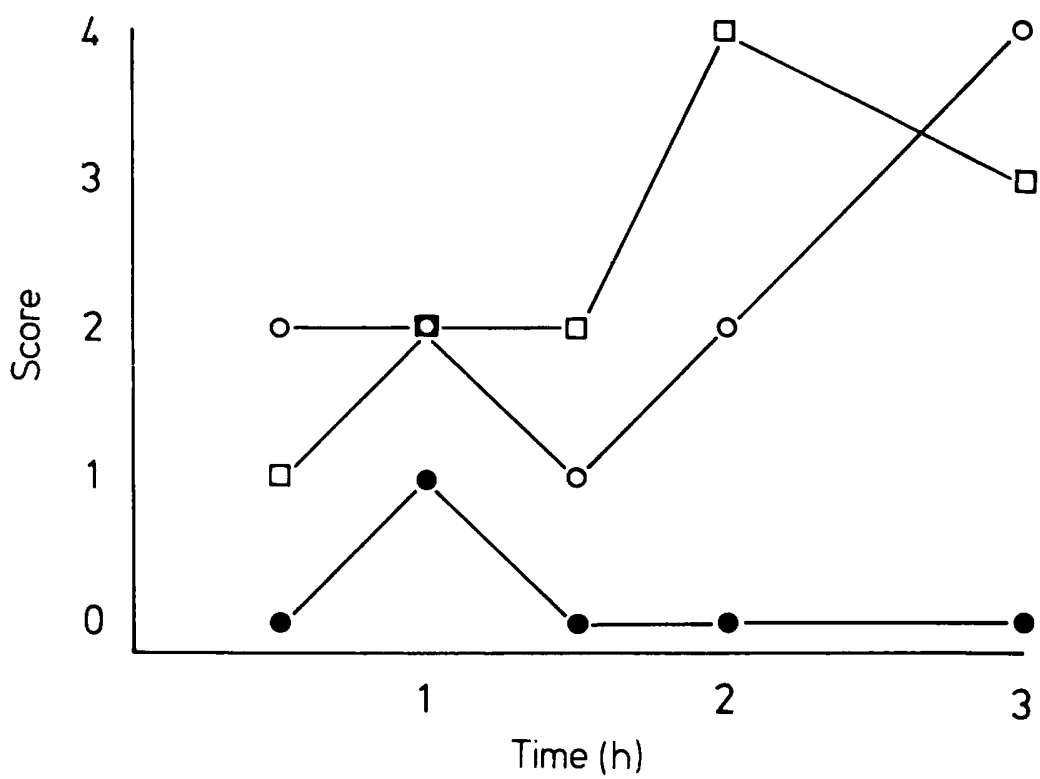

Fig. 6. - Time course of enterotoxin response in suckling mice incubated at $28^{\circ} \mathrm{C}$ given by preparations from enterotoxigenic, $(\mathrm{O}-\mathrm{O}$ and $\mathrm{\square}-\mathrm{\square})$, and non-enterotoxigenic, $(\bullet-\bullet)$, strains of Aeromonas hydrophila. 


\section{Discussion}

This paper reports the first detailed studies of the conditions required for the production of enterotoxins by strains of $A$. hydrophila and their detection in a suckling-mouse assay.

Strains of $A$. hydrophila, grown at $37^{\circ} \mathrm{C}$ for $24 \mathrm{~h}$, produced enterotoxins less regularly in static broth cultures than in broth cultures aerated at speeds from 100 to $300 \mathrm{rpm}$; enterotoxins were produced in shorter periods in broths inoculated from 8-h starter cultures.

Cell-free preparations from aerated broth cultures were assessed for their ability to produce an enterotoxic response after intragastric inoculation of suckling mice, unfurred and less than 6 days old, that were incubated at $28^{\circ} \mathrm{C}$ for $3 \mathrm{~h}$. Our success with the suckling-mouse assay probably resulted from our application of a combined scoring system based on two indices, the IW:BW ratio and the amount of diarrhoea; the use of either alone gave incorrect results with strains of known enterotoxin status. The total scores given in the suckling-mouse assay by non-enterotoxic and enterotoxic preparations were, respectively, zero and two or more.

Preparations that required retesting, because they gave intermediate scores of 1 , were usually those of non-enterotoxigenic strains grown in BHI. The generally higher osmolality of these preparations may have adversely influenced the assay system. Furthermore, BHI-grown preparations often gave scores that were high for diarrhoea and low for IW:BW ratio. Thus, the failure of Cumberbatch et al. (1979) to demonstrate enterotoxic activity for strains of $A$. hydrophila in a suckling-mouse assay may have been due in part to their reliance on IW:BW ratio as the sole criterion for enterotoxic activity of the BHI preparations they used. For these reasons, therefore, we recommend the use of TSB-YE as the growth medium for enterotoxin production.

Stavric and Jeffrey (1976) recommended gastric distension and the absence of blue dye from the intestine as criteria for discrimination of ST-producing strains of $E$. coli. Our findings showed that these variables were not reliable for detection of the enterotoxins of Aeromonas. Although Boulanger, Lallier and Cousineau (1977) reported strains of $A$. hydrophila to be enterotoxin positive in the suckling-mouse test, Cumberbatch et al. (1979) and Dobrescu (1978) did not detect the presence of enterotoxins of $A$. hydrophila by that method. It is not possible to explain the negative results from previously reported studies, however, because of inadequate documentation of the methods used; in particular, none referred to the use of both variables used in our study, i.e., the presence of diarrhoea and the IW: BW ratio.

Our technique allows detection of Aeromonas enterotoxins on a larger scale than is possible with the use of systems such as the rabbit ileal loop or perfusion of rat jejunum in vivo. Because Aeromonas strains produce cytotoxins as well as enterotoxins, cell-culture systems may not be ideal for detection of enterotoxigenic strains. The validation of the suckling-mouse assay for enterotoxins of Aeromonas should simplify epidemiological studies and allow 
clarification of the rôle of enterotoxigenic strains of Aeromonas in diarrhoeal diseases.

We thank Mr M. Atkinson of the School of Pharmacy, South Australian Institute of Technology, Professor V. I. Mathan of the Christian Medical College, Vellore, Mr Md. Imdadul Huq of the International Centre for Diarrhoeal Disease Research, Bangladesh, and Mr P. Worthy of Princess Margaret Hospital for supplying strains of Aeromonas. We thank Miss Sally Dalton-Morgan for excellent technical assistance.

This work received financial support from the TVW Telethon Foundation, Perth, Australia, the Wellcome Trust, London and the National Health and Medical Reseach Council of Australia.

\section{REFERENCES}

Boulanger, Y., LALliER, R. AND COUSINEAU, G. 1977. Isolation of enterotoxigenic Aeromonas from fish. Can. J. Microbiol., 23, 1161.

Cumberbatch, N., Gurwith, M. J., Langston, C., SaCk, R. B. and Brunton, J. L. 1979. Cytotoxic enterotoxin produced by Aeromonas hydrophila: relationship of toxigenic isolates to diarrheal disease. Infect. Immun. 23, 829.

Dean, A. G., Ching, Y. C., Williams, R. G. and Harden, L. B. 1972. Test for Escherichia coli enterotoxin using infant mice: application in a study of diarrhea in children in Honolulu. J. infect. Dis., 125, 407.

DoBRescu, L. 1978. Enterotoxigenic Aeromonas hydrophila from a case of piglet diarrhoea. Zbl. VetMed. B., 25, 713.

SCHUBERT, R. H. W. 1974. In Bergey's manual of determinative bacteriology, 8 th ed., edited by R. E. Buchanan and N. E. Gibbons, Williams \& Wilkins, Baltimore, p. 345.

STAVRIC, S. AND JeFFrey, D. 1976. A modified bioassay for heat-stable Escherichia coli enterotoxin. Can. J. Microbiol., 23, 331. 